\title{
Experiencias de violencia de género en mujeres migrantes bolivianas residentes en Tarapacá, Chile
}

\section{Experiences of gender violence in Bolivian migrant women residing in Tarapacá, Chile}

Mileska Romero* (iD) https://orcid.org/0000-0002-8656-0601

Recibido el 27 de mayo de 2020. Aceptado el 25 de enero de 2022. Publicado el 31 de enero de 2022.

*Autora para correspondencia: Mileska Romero. Correo electrónico: milirom88@gmail.com

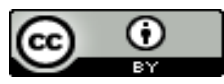

Esta obra está protegida bajo una licencia Creative Commons Atribución 4.0 Internacional.

\begin{abstract}
${ }^{a}$ Universidad Arturo Prat, Magister en Relaciones Internacionales y Estudios Transfronterizos; Pontificia Universidad Católica de Valparaíso, Estudiante de Magister en Derecho, Valparaíso, Chile, correo electrónico: milirom88@gmail.com
\end{abstract}

\section{Resumen}

El artículo aborda los resultados de un estudio de caso sobre las experiencias de violencia que impactan a migrantes bolivianas residentes en Tarapacá, Chile. La investigación se efectuó en 2019 y los objetivos son: comprender cómo la violencia repercute o altera la migración de aquellas mujeres e indagar en el nivel de conocimiento acerca de la institucionalidad chilena y boliviana competente en la materia. El texto se estructura a partir de tres estrategias metodológicas: revisión del estado del arte de los debates sobre la relación entre género, violencia y migración; análisis documental de legislación nacional e internacional y aplicación de entrevistas cualitativas a 10 migrantes que sufrieron violencia por sus parejas. Dentro de los hallazgos se corrobora que efectivamente la violencia de género influye en la decisión de migrar de las entrevistadas.

Palabras clave: violencia de género, marco jurídico, migrantes bolivianas, Tarapacá.

\section{Abstract}

The article addresses the results of a case study on the experiences of violence that affect Bolivian migrants residing in Tarapacá, Chile. The research was carried out in 2019 and the objectives are: to understand how violence affects or alters the migration of those women and to investigate the level of knowledge about the Chilean and Bolivian institutions competent in the matter. The text is structured around three methodological strategies: a review of the state of the art of the debates on the relationship between gender, violence and migration; a documentary analysis of national and international legislation and, application of qualitative interviews to 10 migrants who suffered violence by their partners. Within the findings, we corroborate that gender violence indeed influences the decision to migrate of the interviewees.

Keywords: gender violence, legal frameworks, Bolivian migrants, Tarapacá.

CÓMO CITAR: Romero, M. (2022). Experiencias de violencia de género en mujeres migrantes bolivianas residentes en Tarapacá, Chile [Experiences of gender violence in Bolivian migrant women residing in Tarapacá, Chile]. Estudios Fronterizos, 22, e085. https://doi. org/10.21670/ref.2201085 


\section{Introducción}

Conocer distintas experiencias de violencia vividas por mujeres migrantes bolivianas que residen en la región de Tarapacá, situada en el norte de Chile, ${ }^{1}$ es un tema de gran relevancia tanto en la capital regional, la ciudad de Iquique, como en las demás comunas de la región, por al menos tres razones fundamentales.

Primero, por el aumento y feminización del contingente migratorio en la región. En Chile, el porcentaje de personas extranjeras residentes habituales en el país, al 31 de diciembre de 2020, fue de 1462103 personas. En Tarapacá, en 2020 se estimó un total de 69358 personas extranjeras, 33745 hombres y 35613 mujeres (Instituto Nacional de Estadística \& Departamento de Extranjería y Migración, 2021). Gran parte de esta migración es de origen boliviana y está vinculada a grupos étnicos aymara. Es posible establecer que esta presencia migratoria aymara boliviana en la región se debe a la demanda de mano de obra en la industria minera local, al dinamismo de las actividades comerciales de la Zona Franca de Iquique, a razones de cercanía geográfica, pero también se relaciona con las prácticas culturales en común (Tapia Ladino \& Ramos Rodríguez, 2013; Ovando \& Ramos, 2016).

Segundo, porque del universo de mujeres migrantes que sufren violencia en la región se registran niveles importantes de violencia de género hacia las mujeres bolivianas. ${ }^{2}$ En Tarapacá se encuentran dos casas de acogida dependientes del actual Servicio Nacional de la Mujer y la Equidad de Género de Chile (Sernameg). Estas casas brindan protección a las mujeres víctimas de los delitos de violencia de mayor gravedad. En 2019, 56\% de las residentes eran extranjeras y, entre estas, $68 \%$ eran bolivianas. ${ }^{3}$

Tercero, porque esta experiencia de violencia parece ser un fenómeno que las mujeres enfrentan en los dos lados de la frontera. Según datos de la Encuesta de Prevalencia y Caracterización de la Violencia contra las Mujeres (Epcvcm) de 2016, aplicada por el Instituto Nacional de Estadísticas del Estado Plurinacional de Bolivia (2018), al interior de este país, en el ámbito privado, 393370 mujeres vivieron algún episodio de violencia por su pareja o expareja. Esta cifra representa $51.9 \%$ de un total de 757408 mujeres solteras de 15 años o más edad que, en 2016, residían en Bolivia. El tipo de violencia más común, relatada por las mujeres en la encuesta, fue la psicológica. De las mujeres solteras, $46.5 \%$ relató sufrir este tipo de violencia, mientras $21.2 \%$ relató sufrir violencia sexual, $16.8 \%$, violencia física y $12.2 \%$ violencia económica. La mayoría de las mujeres que alegó sufrir estas violencias tenía entre 29 y 59 años. De las denunciantes, $67.6 \%$ hizo una demanda formal. No obstante, $56.4 \%$ de los casos no obtuvo ninguna sanción y solo se dio una sentencia penal a $35 \%$ de

\footnotetext{
${ }^{1}$ Desde una perspectiva histórica, la región de Tarapacá ha sido un lugar de tránsito y movilidades fronterizas, incluso desde antes del establecimiento del Estado nación (Tapia Ladino \& Ramos Rodríguez, 2013). Toda la región pertenecía a Perú y fue anexada a Chile tras el término de la guerra del Pacífico (1879-1883). El territorio de la región colinda al norte con la región chilena de Arica y Parinacota, y al sur con la región de Antofagasta, pero sus tierras orientales colindan con el centro oeste de Bolivia, que comparten con este país zonas rurales de altura ocupadas mayormente por poblaciones aymara (Ovando \& Ramos, 2016).

${ }^{2}$ Esta realidad sigue a una dinámica nacional. Según consta en el Boletín $\mathrm{N}^{0} 3$ de violencia contra la mujer (Subsecretaría de Prevención del Delito, 2016), el delito de violencia intrafamiliar se encuentra en ascenso y ha estado entre las 10 categorías de registros policiales más frecuentes en el país entre 2005 y 2016.

${ }^{3}$ Datos facilitados por el Sernameg específicamente para esta investigación a través de solicitud directa (2019).
} 
dichas denuncias. Entre 2013 y 2018 se registraron 555 casos de feminicidios en Bolivia (Coordinadora de la Mujer, 2019).

La normativa internacional de protección a las mujeres y a las trabajadoras migrantes y sus familias ha sido firmada y ratificada por el Estado chileno. Además, se han dictado normativas internas que sancionan delitos que atentan contra la vida e integridad física y psíquica de las mujeres. No obstante, estas normativas no han logrado frenar la violencia contra las mujeres (sean ellas migrantes o no). Con esto en mente, se desarrolla un estudio de caso con el objetivo de comprender cómo la violencia impacta o altera la migración de las mujeres bolivianas: desde la decisión de dejar su país de origen, hasta el arraigo en territorio chileno. Se buscó, además, indagar en el nivel de conocimiento acerca de la institucionalidad chilena y boliviana que, desde el punto de vista formal, debieran garantizar los derechos a la integridad física y psíquica de estas mujeres.

El texto se organiza en cinco apartados subsecuentes a esta introducción. El primero sitúa la conceptualización sobre género y migraciones en las ciencias sociales. El segundo ofrece el marco jurídico nacional e internacional vigentes en Chile en materia de protección de las trabajadoras migrantes. En el tercero se sintetiza el perfil de las mujeres bolivianas entrevistadas (residentes en la región de Tarapacá) y se analizan sus entrevistas, explicando cómo ellas relacionan la experiencia de la violencia con la decisión de migrar. En el cuarto apartado se analiza el nivel de conocimiento y experiencia de las migrantes respecto al funcionamiento de la institucionalidad en la materia de protección a la violencia contra las mujeres. Para finalizar con las conclusiones.

\section{Respecto a la metodología}

El estudio que dio origen al presente artículo estuvo estructurado a partir de tres estrategias metodológicas. Primero, se efectuó una revisión de estado del arte de los debates en las ciencias sociales sobre la relación entre género, violencia y migración. El objetivo era establecer las definiciones analíticas que guiarían tanto las preguntas, como las hipótesis de investigación. En un segundo momento, se realizó, además, una revisión detallada de la legislación nacional y de los instrumentos internacionales, ratificados por Chile y vigentes, en lo que concierne a la protección de las mujeres migrantes. En la tercera etapa metodológica de la investigación, que se realizó en el segundo semestre de 2019, se contactó con el servicio público de la región de Tarapacá que atiende a mujeres víctimas de violencia. Se solicitaron informaciones y estadísticas de atención de los programas dependientes de la Dirección Regional de Sernameg Tarapacá, en la búsqueda de registros que visibilizaran la problemática de la violencia de género en mujeres migrantes. Además, se realizó una entrevista cualitativa a un agente que labora en la Dirección Regional de dicho servicio. Una vez recibidos y analizados estos datos, y para tener acercamiento a la experiencia de violencia de las mujeres, se efectuaron 10 entrevistas cualitativas semiestructuradas a migrantes bolivianas residentes en la región que habían sufrido violencia por sus parejas. Las comunicaciones con estas mujeres fueron realizadas gracias a las redes de contacto con las comunidades migrantes locales. Estas entrevistas fueron anonimizadas para proteger la identidad de las informantes, transcriptas y analizadas. Los relatos de las mujeres constituyen los insumos de los apartados empíricos de este artículo. 
A partir de todo este material, el presente texto pretende ser un aporte al estudio de las migraciones, al explorar el problema de violencia de género sufrida por mujeres migrantes bolivianas en Tarapacá, con un enfoque en el marco jurídico del Estado chileno.

\section{Género, violencia y migraciones internacionales}

El presente apartado discute los conceptos que definen la perspectiva analítica del estudio de caso llevado a cabo. Estos conceptos se dividen en tres campos: el género, las violencias sufridas por las mujeres y las migraciones femeninas.

El debate sobre el género es polisémico en las ciencias sociales y ha estado presente en disciplinas como la sociología y antropología desde fines del siglo xix. Actualmente, las ciencias sociales hablan del género como la construcción social y cultural de las diferencias sexuales entre los seres humanos. Esta perspectiva teórica fue introducida por las feministas anglófonas en la década de 1970. Dentro de este uso se entiende que el término alude al comportamiento y a los rasgos de la personalidad, los cuales dejan marcas y construyen el cuerpo. El género ha venido empleándose cada vez más para hacer referencia a toda construcción social relacionada con la distinción masculino/femenino, entre ellas las que separan el cuerpo "masculino" del cuerpo "femenino" (Nicholson, 1994, en Tubert, 2003, p. 48). Este debate asume que el sexo es biológicamente determinado, mientras el género es una construcción social.

Para autoras como Stolke (2004) y Chiarotti (2006), los estudios de género y su incorporación en las ciencias sociales tienen su antecedente en Simone de Beauvoir (1945 [1997]), quien planteó que no se nace mujer, sino que se llega a serlo. A partir de este postulado se comenzó a cuestionar la diferencia entre sexo y género, ya que hombres y mujeres serían el resultado de una construcción cultural y no biológica.

Pero, además, estas asimetrías se amparan en desigualdades de poder que están vinculadas a la potestad masculina de violencia contra las mujeres, la cual se ha agudizado con la intensificación del patriarcado en diversos países de América Latina, entre ellos, Bolivia.

En ese sentido, al seguir la línea de que el género es una construcción cultural y que, por ende, se da en contextos relacionales específicos, diversas autoras plantean que la identidad femenina se construye no solo a partir de la asignación de roles y la diferenciación respecto del hombre, sino también a través de la diferenciación con otras mujeres: "en una sociedad donde las relaciones de raza y de clase son asimétricas, un sujeto se transforma en mujer también en oposición a otras mujeres" (Stephenson, 1993, en Peredo Beltrán, 2004, p. 44). Estas autoras vienen observando que las asimetrías que históricamente han regido la relación entre hombres y mujeres se ven agudizadas en contextos pluriétnicos, multiculturales y plurilingües, como los que caracterizan a la mayoría de los países latinoamericanos (Sichra, 2004, en Lamas, 2007, p. 134).

Rossana Barragán (1996), con base en la recopilación de disolución de vínculos matrimoniales en la capital de Bolivia, planteó la hipótesis de que las relaciones de género verticales, junto a nuevas condiciones relacionadas con la urbanización de las áreas andinas, modificaron las relaciones de género tradicionales en los grupos culturales como los aymara, lo que las llevó hacia un patriarcado más intenso.

Su estudio postuló que el proceso de colonización en América Latina articuló una matriz de dominación patriarcal, patrimonial y colonial, lo que produjo relaciones 
sociales asimétricas. En ellas, el hogar emergió como el espacio donde el varón hace ejercicio irrestricto de esta misión civilizadora que le encarga la sociedad y la ley sobre la base de la contraposición entre hombre-sociedad-cultura, por un lado, y, por el otro, mujer-naturaleza (Peredo Beltrán, 2004). Estudios recientes comprueban la actualidad de estas máximas históricas. Por ejemplo, a través de trabajos en terreno efectuados en Bolivia (en las ciudades de Cochabamba y en Santa Cruz), Guaygua y Castillo (2008) advierten que las mujeres están convencidas de que las funciones hechas por los varones serán siempre más importantes que las de sus hermanas o compañeras de trabajo, contribuyendo de esa manera a la desigualdad y desequilibrio de los cuales ellas mismas son víctimas.

Asimismo, diversos estudios observan que, además de la búsqueda por mejores situaciones de vida y económicas, el deseo de huir de la violencia doméstica es también un factor que impulsa la migración femenina. Para muchas migrantes, salir de su país es la única opción para escapar a la dinámica del maltrato (Espín, 2010; Asakura \& Torres Falcón, 2013). No obstante, "la violencia de género es una realidad que atraviesa fronteras geográficas, culturales, económicas” (Asakura \& Torres Falcón, 2013, p. 76). Es decir, se encuentra presente en el diario vivir, manifestándose de diferentes formas y, en muchos casos, sucede de modo indistinto en el lugar de origen, durante el viaje migratorio y en el lugar de arraigo de las migrantes. Estos aspectos nos llevan a indagar sobre cómo han sido tratadas las relaciones de género en los estudios de la migración internacional.

Para efecto de esta investigación, se toma en consideración la definición de violencia de género entregada por la Asamblea General de las Naciones Unidas que, en diciembre de 1993, aprobó la Declaración sobre la eliminación de la violencia contra la mujer (Res. A.G. 48/104, onU, 1994), primer instrumento internacional de derechos humanos que define la violencia de género, en el artículo 1, como

todo acto de violencia basado en la pertenencia al sexo femenino que tenga o pueda tener como resultado un daño o sufrimiento físico, sexual o psicológico, para la mujer, así como las amenazas de tales actos, la coacción o la privación arbitraria de la libertad, tanto, si se producen en la vida pública como en la vida privada.

En el contexto latinoamericano de la década de 1990, los flujos migratorios desde los países de la región han presentado una fuerte tendencia a la feminización (Lube Guizardi et al., 2018). Es así, como la autora Elaine Acosta González (2013) plantea la migración como una oportunidad para escapar o cuestionar el sistema de normas y pautas de socialización en el que las mujeres latinoamericanas despliegan sus proyectos de vida en las sociedades de origen. Y, además, se postula que esta migración femenina latinoamericana no obedece solo a motivaciones económicas, sino a otras razones, como la posibilidad de liberarse de los controles androcéntricos y de las sobrecargas provocadas por las obligaciones referentes a los roles de madre y cónyuge (Lamas, 2007; Tapia Ladino, 2011).

A fin de contextualizar la investigación, a partir de las entrevistas aplicadas se extrajeron indicadores sociodemográficos de las entrevistadas, en este punto es relevante considerar los postulados de Herrera (2013), quien afirma que: "[...] el género se incorpora como una dimensión transversal, junto con la clase, el origen étnico, la raza y otros marcadores sociales de desigualdad, y como elemento constitutivo del campo transnacional" (p. 476). En los estudios actuales de las migraciones femeninas, el enfoque de la interseccionalidad se ha vuelto una perspectiva central, que permite teorizar sobre 
el vínculo entre género y migraciones (Nash, 2008; Anthias, 2012; Bastia, 2014, en Parella \& Reyes 2019) y vislumbrar las diferentes formas de discriminación que configuran experiencias y prácticas de las mujeres migrantes internacionales. Si bien, en esta investigación no se utilizó como categoría analítica, es relevante tenerlo presente para efectos de la comprensión del impacto de la violencia en la vida de las entrevistadas.

Estas transformaciones han tenido gran relevancia en el contexto boliviano. A fines del siglo xx, en Bolivia se percibía un aumento acelerado de la migración internacional. Además, estos flujos migratorios dejaron de ser principalmente masculinos, consolidándose un acelerado incremento de la migración femenina por motivos laborales (debido a la crisis económica vivida por Bolivia). Así, en la primera década del siglo xxi, Bolivia estuvo entre los países latinoamericanos que más recibían remesas internacionales enviadas por migrantes (Guaygua et al., 2010). Esta nueva movilidad femenina boliviana cultivó en muchas mujeres el deseo de romper con las normas establecidas por vínculos patriarcales y las conductas arraigadas del machismo a través de la migración internacional (Hinojosa et al., 2000; Guaygua \& Castillo, 2008; Tapia Ladino, 2011; Leiva Gómez, 2015). Pero, simultáneamente, esta inmigración femenina conlleva una acumulación de factores de riesgo, tales como la ocupación en trabajos más precarios y el elevado impacto sobre la salud física y psicológica, la discriminación en diferentes situaciones en el país de destino, la relación con el estatus migratorio y la búsqueda de redes de apoyo social tras el desarraigo familiar (Vives-Cases et al., 2009; Acosta González, 2013).

En el apartado siguiente se revisa el marco jurídico que entrega los lineamientos en materia de violencia de género.

\section{Marco jurídico e institucional: la protección de las mujeres y de las migrantes}

\section{Marco jurídico internacional}

Con la Declaración universal de los derechos humanos (DUDH), firmada en 1948, se han sentado consensos mínimos sobre la regulación internacional de los actos atentatorios contra la vida y la integridad física y psíquica de las personas, para establecer, además, el principio de igualdad entre hombres y mujeres. Estos principios fueron plasmados en diferentes convenciones firmadas y ratificadas por varios Estados, incluidos Chile y Bolivia, lo que norma la obligación de respetar, proteger y hacer efectivos los derechos para todos los seres humanos, sin distinción. Así, desde una perspectiva jurídica, tanto la violencia contra la mujer como las diversas formas de discriminación y explotación de las poblaciones migrantes han sido entendidas, a partir de la segunda mitad del siglo xx, como vulneraciones de los derechos humanos (DDHH) (Rico, 1996). Desde la declaración de los DDHH se han celebrado diversas convenciones internacionales 
que aportan regulaciones ${ }^{4}$ en estas materias. En lo que concierne al derecho de las migrantes y de las mujeres se destacan dos tratados principales. Por un lado, la Convención internacional para la protección de los derechos humanos de los trabajadores migrantes y sus familias (CMW, por sus siglas en inglés, ratificada por Chile en 2005) y, por otro lado, la Convención sobre eliminación de todas las formas de discriminación hacia las mujeres (CEDAw, por sus siglas en inglés, ratificada por Chile en 1989), cuyo protocolo, después de 18 años de estar en el Congreso, fue ratificado por el Senado en diciembre de 2019.

Actualmente hay cierto consenso entre los organismos internacionales de los DDHH en el sentido de utilizar las definiciones de violencia contra la mujer que fueron acordadas en la Convención interamericana para prevenir, sancionar y erradicar la violencia contra la mujer, "Convención Belem Do Pará" (firmada y ratificada tanto por Chile, como por Bolivia en 1994). En su artículo 1, la convención estipula dicha violencia como "cualquier acción o conducta, basada en su género, que cause muerte, daño o sufrimiento físico, sexual o psicológico a la mujer, tanto en el ámbito público como en el privado".

\section{Marco jurídico interno en Chile}

En Chile, la legislación vigente en materia de migración es el Decreto Ley No 1094 (de 1975) y su respectivo reglamento, establecido por el Decreto Supremo $\mathrm{N}^{\circ} 597$ (de 1984). ${ }^{5}$

A su vez, la primera ley en materia de violencia intrafamiliar fue la $\mathrm{N}^{\circ} 19325$ de 1994. Esta norma se derogó en 2005, dando paso a la ley $\mathrm{N}^{\circ} 20066$, que establece el objetivo de prevenir, sancionar y erradicar la violencia intrafamiliary otorgar protección a las víctimas. Lo más relevante de esta ley es que este tipo de violencia dejó de ser tratada jurídicamente como un problema del ámbito privado y se elevó al ámbito del derecho público, lo que, no obstante, no logró frenar la escalada de la violencia contra la mujer en el país (Centro de Derechos Humanos, 2017). Asimismo, es destacable

\footnotetext{
${ }^{4}$ Entre estas: Pacto internacional de derechos civiles y políticos; Pacto internacional de derechos económicos, sociales y culturales (PIDCP y PIDESC, respectivamente, ambos ratificados por Chile en 1972); Declaración americana de derechos y deberes del hombre (1948); Convención americana sobre derechos humanos (CADH, también conocido como Pacto de San José de Costa Rica, ratificada por Chile en 1990); Protocolo adicional a la convención americana sobre derechos humanos en materia de derechos económicos, sociales y culturales (Protocolo de San Salvador, firmado por Chile en 2001); Convención internacional sobre la eliminación de todas las formas de discriminación racial (ratificado por Chile en 1971); Convención interamericana contra el racismo, la discriminación racial y otras formas conexas de intolerancia (firmado por Chile en 2015); Convención interamericana contra toda forma de discriminación e intolerancia (firmado por Chile en 2015); Estatuto de Roma de la Corte Penal Internacional (ratificado por Chile en 2009); Convenio $N^{\circ} 169$ sobre pueblos indígenas y tribales en países independientes (OIT $\mathrm{N}^{\circ}$ 169, ratificado por Chile en 2008); Convención contra la tortura (CAT, ratificada por Chile en 1988); Convención de las Naciones Unidas contra la delincuencia organizada transnacional (suscrita en Palermo); Protocolo contra el tráfico ilícito de migrantes por tierra, mar y aire, que complementa la convención de las Naciones Unidas contra la delincuencia organizada transnacional y el Protocolo para prevenir, reprimir y sancionar la trata de personas, especialmente mujeres y niños, que complementa la convención de las Naciones Unidas contra la delincuencia organizada transnacional, (todos ratificados por Chile en 2004); Convenio sobre las trabajadoras y los trabajadores domésticos (Convenio № 189 de la OIT, ratificado por Chile en 2015); y, el convenio sobre la eliminación de la violencia y el acoso en el mundo del trabajo (Convenio $\mathrm{N}^{\circ} 190$ de la OIT, pendiente de ratificación en Chile).

${ }^{5}$ Con fecha 11 de abril de 2021, se promulgó la nueva ley de migraciones $N^{0} 21325$, sin embargo, entrará en vigencia hasta la publicación de su reglamento. Importante es mencionar que una de las novedades de la normativa es que se dificulta el cambio de categoría migratoria, lo que sin duda precarizará las condiciones de vida de las migrantes (Ministerio del Interior y Seguridad Pública, 2021).
} 
que esta ley limita, en su artículo 5, su ámbito de protección a la violencia sufrida por mujeres que sean o hayan sido cónyuges o convivientes de su agresor, o que tengan hijos/as en común con el mismo, dejando desprotegidas a las víctimas de violencia sufrida en el contexto de relaciones afectivas sin vínculo matrimonial o convivencia. ${ }^{6}$ Respecto al acto de violencia más grave, el delito de femicidio, introducido en el marco legal chileno en 2010, en un comienzo fue definido jurídicamente como el homicidio cometido contra la mujer que es o ha sido cónyuge o conviviente del autor del crimen. Sin embargo, después de 10 años, el tipo penal se amplió para cualquier homicidio por razones de género, así aplica para cualquier prototipo de relación que una mujer tenga con su agresor. Esta modificación legal se condice con el concepto instalado por Lagarde (2006).

En lo que concierne a la institucionalidad estatal, en 1969 se creó en Chile la Oficina Nacional de la Mujer, cuyo objetivo fue promover la igualdad entre hombres y mujeres. En 1991 se fundó el Servicio Nacional de la Mujer y, finalmente, en 2016 se instituyó el Ministerio de la Mujer y la Equidad de Género, del que el Servicio quedó subordinado y primordialmente ejecuta funciones técnicas, ${ }^{7}$ puesto que la competencia en incidencia en políticas públicas queda en la esfera del Ministerio. Parte importante del despliegue de estas instituciones a nivel local y regional se da a través de las casas de acogida. Se trata de residencias temporales para mujeres mayores de 18 años (e hijo de hasta 14 años) que se encuentran en situación de violencia calificada como grave o vital. Existe también una casa de acogida para

\footnotetext{
${ }^{6}$ Desde enero de 2017 y hasta la fecha de publicación de este texto, se discute en el Senado chileno el proyecto de ley denominado "Sobre el derecho de las mujeres a una vida libre de violencia" (boletín N ${ }^{\circ}$ 11077-07) (Cifuentes \& Weidenslaufer, 2019). Este redefine el concepto de violencia contra las mujeres, en su artículo 2, como
}

cualquier acción u omisión, sea que tenga lugar en el ámbito público o en el privado, basada en el género y ejercida en el marco de las relaciones de poder históricamente desiguales que emanan de los roles diferenciados asignados a hombres y mujeres, que resultan de una construcción social, cultural, histórica y económica, que cause o pueda causar muerte, menoscabo físico, sexual, psicológico, económico o de otra clase a las mujeres, incluyendo la amenaza de realizarlas y en general cualquier conducta que menoscabe o amenace sus derechos.

Asimismo, en sus artículos 3 y 4 reconoce diferentes tipos de violencia, entre estas: física, psicológica, sexual, económica, simbólica, institucional, política, laboral e indirecta, que pueden tener lugar dentro de los ámbitos privados y/o públicos.

${ }^{7}$ El artículo 2 de la ley № 19023 señala las competencias de este servicio, entre estas, las más importantes son:

El Servicio Nacional de la Mujer y la Equidad de Género es el organismo encargado de ejecutar las políticas, planes y programas que le encomiende el Ministerio de la Mujer y la Equidad de Género.

En especial, le corresponderán las siguientes funciones y atribuciones:

a) Implementar políticas, planes y programas con pertinencia cultural, orientados a la equidad de género, a la igualdad de derechos y a procurar eliminar toda forma de discriminación arbitraria contra las mujeres, incluido el Plan Nacional de Igualdad entre Hombres y Mujeres; $b$ ) Ejecutar programas que fomenten el desarrollo integral de las mujeres y la equidad de género en los distintos ámbitos de la vida nacional; c) Ejecutar programas que velen por la plena participación de las mujeres en la vida laboral, social, económica y cultural del país, y en los cargos de elección popular y funciones públicas, como asimismo, aquellos que promuevan el desarrollo y autonomía de las mujeres; $d$ ) Ejecutar programas destinados a prevenir, erradicar y sancionar la violencia contra las mujeres e intrafamiliar [...]. 
mujeres vulneradas por el delito de trata de personas y mujeres migrantes en situación de explotación. ${ }^{8}$

A partir de 2009, el Estado chileno ha buscado incorporar la "perspectiva de género" en el análisis y tratamiento del fenómeno migratorio, partiendo del supuesto de que el proceso migratorio se vive de forma distinta por hombres y mujeres. Se observa, además, que son las migrantes, por el solo hecho de ser mujer, quienes se encuentran expuestas a más vulneraciones de derechos, tanto en la esfera pública, como en la íntima. Dicha perspectiva propone comprender el género "como la institucionalización de la diferencia sexual, o sea, el entramado sociocultural que se teje sobre la diferencia sexual" (Chiarotti, 2006, p. 7).

En el marco de estos cambios jurídicos, la Resolución Exenta $N^{\circ} 80388$ (del 16 de diciembre de 2009), del entonces Servicio Nacional de la Mujer (Sernam, hoy Sernameg), aprobó el convenio de colaboración y acción conjunta entre el Ministerio del Interior y Seguridad Pública y aquel servicio. En este convenio se establece que el Sernam tomará las medidas institucionales para facilitar la atención y protección en las casas de acogida existentes a nivel nacional, de las mujeres migrantes, solicitantes de refugio y refugiadas que sean víctimas de violencia intrafamiliar. Asimismo, se estableció que el Sernam brindaría, en sus centros de la mujer, atención a las extranjeras víctimas de violencia intrafamiliar, independientemente de cual fuera su situación administrativa de residencia (Ministerio del Interior de Chile \& Servicio Nacional de la Mujer, 2009).

\section{Marco jurídico interno de Bolivia}

En Bolivia, a su vez, en 1995 se publicó la Ley contra la violencia en la familia o doméstica (Ley $\mathrm{N}^{\circ}$ 1674). En su artículo 4, esta normativa definía por violencia en la familia o doméstica la agresión física, psicológica o sexual cometida por el cónyuge o conviviente; los ascendientes, descendientes, hermanos, parientes civiles o afines en línea directa y colateral; los tutores, curadores o encargados de la custodia. Aquí, las definiciones son más abiertas y no contemplan solo a las relaciones formales entre un hombre y una mujer. En su artículo 5, la ley lo hacía más explícito. Al profundizar en estas definiciones que permitían abrir el espectro de la violencia considerada por la ley, el artículo 6 detallaba la violencia física, violencia psicológica y violencia sexual. Asimismo, se consideran hechos de violencia en la familia cuando los progenitores, tutores o encargados de la custodia pongan en peligro la integridad física o psicológica de los menores. Igualmente, se consideran actos de violencia en la familia los realizados contra los mayores incapacitados.

Los hechos de violencia en la familia o doméstica, comprendidos en la ley, que no constituyeran delitos tipificados en el Código Penal, son sancionados con multa o arresto. En 2013, se dictó la actual ley integral No 348 (Asamblea Legislativa Plurinacional, 2013) para garantizar a las mujeres una vida libre de violencia. Su objeto, señalado en su artículo 2, es establecer mecanismos, medidas y políticas integrales de prevención, atención,

\footnotetext{
${ }^{8}$ Al ser consultado Sernameg, respecto si hay casos de femicidios de mujeres extranjeras durante los años 2017, 2018 y 2019 a nivel nacional y regional y si dentro de ese universo hay mujeres bolivianas, indicó que: en el caso de femicidios frustrados entre los tres años indicados, hubo un total de 324 casos: 297 chilenas, 27 extranjeras, de ellas 5 son bolivianas y residentes en lquique. Del total de casos de femicidios consumados durante ese mismo periodo a nivel nacional se registró la muerte de 123 mujeres: 106 chilenas, 17 extranjeras, de estas, 3 bolivianas. Respecto al registro de mujeres víctimas de trata de personas atendidas durante el mismo periodo en la región, señaló que se atendió uno en 2017 y uno en 2019.
} 
protección y reparación a las mujeres en situación de violencia. Se estipula, además, la persecución y sanción a los agresores, con el fin de garantizar a las mujeres una vida digna y el ejercicio pleno de sus derechos, declarando que para el Estado Plurinacional de Bolivia es una prioridad la erradicación de la violencia de género. En su artículo 7, la ley avanza hacia la tipificación de una amplia gama de violencias, entre estas: física, sexual, psicológica, económica y patrimonial, dentro de los ámbitos, familiar, laboral, institucional, educacional, de salud, mediático, político, social y cultural.

Se considera relevante destacar que esta ley introduce nuevos tipos penales al visibilizar las diferentes violencias que sufre la mujer, entre estos: $a$ ) incumplimiento de deberes de protección a mujeres en situación de violencia, destinados a las y los servidores públicos que propicien la impunidad de cualquier forma y recibirán sanción alternativa o inhabilitación de función pública (Artículo 154 bis), b) el feminicidio, a quien mate a una mujer en las circunstancias descritas en la ley, sanción de 30 años sin derecho a indulto (Artículo 252 bis), $c$ ) esterilización forzada (Artículo 271 bis), $d$ ) violencia económica (Artículo 250 bis), e) homicidio suicidio (Artículo 256) y acoso sexual (Artículo 312 quater).

De lo expuesto, se puede concluir que ambos Estados, en la década de 1990, dieron un paso importante al hacer el esfuerzo de actualizar su normativa interna a los parámetros internacionales. Sin embargo, al momento de la redacción de este artículo, el marco normativo chileno se encuentra en evidente retraso respecto a consagrar una vida libre de violencia para las mujeres, que busque una igualdad efectiva entre hombres y mujeres.

Esto se refleja en que las experiencias de violencia siguen siendo una constante en las trayectorias de las mujeres en ambos países, a continuación se leerá en los relatos de las migrantes bolivianas en Tarapacá.

\section{Las experiencias de violencia}

En la presente sección se revisan los datos empíricos levantados en este estudio de caso a través de la aplicación de entrevistas cualitativas semiestructuradas a 10 mujeres bolivianas residentes en la región de Tarapacá. La muestra se centró en migrantes que han sufrido violencia de pareja en Bolivia y/o en Chile. Para analizar los hallazgos, este apartado estará dividido en dos partes. Primero, se da a conocer el perfil de las entrevistadas para luego conocer sus relatos sobre las experiencias de violencia vividas y cómo estas han influido en la decisión de migrar.

\section{El perfil}

Las mujeres entrevistadas (véase Tabla 1) son provenientes de varios lugares de Bolivia: Santa Cruz de la Sierra (3), Cochabamba (2), Sucre (2), La Paz (1), El Alto (1) y El Beni/Riveralta (1). Todas se encontraban en edad económicamente activa, pero sus edades variaban. Entre ellas, una tenía entre 51 y 55 años, dos tenían entre 47 y 50 años, dos entre 31 y 35 años, otras dos entre 26 y 30 años, mientras tres tenían entre 20 y 25 años. De ellas, nueve se encontraban en situación migratoria regular y llevaban más de dos años residiendo en Chile. Sus lugares de residencia se circunscribían a tres comunas de la región de Tarapacá: Iquique (6), Alto Hospicio (2) y Pozo Almonte (2). En lo que concierne a su acceso a la educación formal, una de ellas relató tener la 
enseñanza básica completa y una tener la enseñanza media incompleta. Cinco de ellas había concluido la enseñanza media y tres tenían la enseñanza superior inconclusa.

Tabla 1. Datos sociodemográficos de las entrevistadas

\begin{tabular}{|c|c|c|c|c|c|c|c|c|c|c|}
\hline $\begin{array}{l}\text { Núm. } \\
\text { entrevista }\end{array}$ & $\begin{array}{l}\text { Edad } \\
\text { años }\end{array}$ & $\begin{array}{l}\text { Estado } \\
\text { civil }\end{array}$ & $\begin{array}{c}\text { Nivel } \\
\text { estudios }\end{array}$ & $\begin{array}{l}\text { Trabajo } \\
\text { remunerado } \\
\text { fuera del } \\
\text { hogar }\end{array}$ & $\begin{array}{l}\text { Situación } \\
\text { migratoria } \\
\text { en Chile }\end{array}$ & $\begin{array}{c}\text { Núm. } \\
\text { de } \\
\text { hijos }\end{array}$ & $\begin{array}{l}\text { Ciudad } \\
\text { de } \\
\text { origen }\end{array}$ & $\begin{array}{l}\text { Ciudad de } \\
\text { residencia } \\
\text { en Tarapacá }\end{array}$ & $\begin{array}{l}\text { Tipo de } \\
\text { violencia }\end{array}$ & $\begin{array}{c}\text { Se declara } \\
\text { pertenecer } \\
\text { a pueblo } \\
\text { originario }\end{array}$ \\
\hline 1 & 51 & Casada & $\begin{array}{l}\text { Superiores } \\
\text { incompletos }\end{array}$ & Sí & Regular & 3 & $\mathrm{La} \mathrm{Paz}$ & Iquique & $\begin{array}{c}\text { Física } \\
\text { Psicológica } \\
\text { Sexual } \\
\text { Económica } \\
\text { Institucional }\end{array}$ & No \\
\hline 2 & 32 & Casada & Básico & No & Regular & 2 & $\begin{array}{l}\text { Cocha- } \\
\text { bamba }\end{array}$ & Iquique & $\begin{array}{c}\text { Física } \\
\text { Psicológica } \\
\text { Económica }\end{array}$ & No \\
\hline 3 & 34 & Casada & $\begin{array}{c}\text { Media } \\
\text { incompleta }\end{array}$ & Sí & Regular & 3 & $\begin{array}{l}\text { Santa } \\
\text { Cruz }\end{array}$ & Iquique & $\begin{array}{c}\text { Física } \\
\text { Psicológica }\end{array}$ & No \\
\hline 4 & 23 & Soltera & Medios & Sí & Regular & 2 & $\begin{array}{l}\text { Santa } \\
\text { Cruz }\end{array}$ & Iquique & $\begin{array}{c}\text { Física } \\
\text { Psicológica } \\
\text { Económica } \\
\text { Sexual } \\
\text { Institucional }\end{array}$ & No \\
\hline 5 & 29 & Casada & Medios & Sí & Regular & 2 & Sucre & $\begin{array}{l}\text { Pozo Al- } \\
\text { monte }\end{array}$ & $\begin{array}{c}\text { Física } \\
\text { Psicológica } \\
\text { Económica } \\
\text { Institucional }\end{array}$ & Sí \\
\hline 6 & 22 & Soltera & Medios & Sí & Regular & 0 & Sucre & $\begin{array}{l}\text { Pozo Al- } \\
\text { monte }\end{array}$ & $\begin{array}{c}\text { Física } \\
\text { Psicológica } \\
\text { Económica } \\
\text { Sexual } \\
\text { Laboral }\end{array}$ & Sí \\
\hline 7 & 49 & Viuda & Medios & Sí & Regular & 4 & $\begin{array}{l}\text { Cocha- } \\
\text { bamba }\end{array}$ & $\begin{array}{l}\text { Alto Hos- } \\
\text { picio }\end{array}$ & $\begin{array}{c}\text { Física } \\
\text { Psicológica } \\
\text { Económica } \\
\text { Sexual }\end{array}$ & Sí \\
\hline 8 & 24 & Soltera & $\begin{array}{l}\text { Superiores } \\
\text { incompletos }\end{array}$ & No & Irregular & 1 & El Alto & Iquique & $\begin{array}{c}\text { Física } \\
\text { Psicológica }\end{array}$ & Sí \\
\hline 9 & 27 & Soltera & Medios & Sí & Regular & 1 & $\begin{array}{l}\text { Santa } \\
\text { Cruz }\end{array}$ & Iquique & $\begin{array}{l}\quad \text { Física } \\
\text { Psicológica } \\
\text { Económica } \\
\text { Sexual }\end{array}$ & No \\
\hline 10 & 48 & $\begin{array}{l}\text { Divor- } \\
\text { ciada }\end{array}$ & $\begin{array}{l}\text { Superiores } \\
\text { incompletos }\end{array}$ & Sí & Regular & 5 & $\begin{array}{l}\text { El Be- } \\
\text { ni-Rive- } \\
\text { ra Alta }\end{array}$ & $\begin{array}{l}\text { Alto } \\
\text { Hospicio }\end{array}$ & $\begin{array}{c}\text { Física } \\
\text { Psicológica } \\
\text { Laboral } \\
\text { Económica } \\
\text { Institucional }\end{array}$ & No \\
\hline
\end{tabular}

Fuente: elaboración propia 
$\mathrm{Al}$ indagar sobre sus experiencias, todas las entrevistadas relataron haber vivido hechos de violencia física y psicológica. Ocho de ellas evidenciaron haber sufrido violencia económica, a pesar de desarrollar actividades remuneradas independientes de las de su pareja o marido. Cinco de ellas manifestaron haber padecido violencia sexual; mientras cuatro declararon haberse sentido violentadas por alguna institución. Dos de ellas, cuando fueron consultadas sobre otras dificultades vividas en Chile, mencionaron haber sido vulneradas laboralmente. A continuación, analizaremos sus relatos sobre estas realidades.

\section{Violencia y trayectorias vitales femeninas}

En esta sección se expone cómo, en los relatos de las migrantes entrevistadas, la violencia aparece de forma transversal, en diferentes momentos de sus trayectorias vitales. Sus narraciones permiten establecer al menos cinco observaciones empíricas sobre sus experiencias de la violencia.

Primero, todas las entrevistadas relataron que sufrieron violencia de manera directa o indirecta durante su niñez, en el seno de sus familias de origen. Estas violencias eran perpetradas por las figuras masculinas, mayormente por los padres, oprimiendo a las figuras femeninas (Segato, 2003) (especialmente a las madres, pero también a las propias entrevistadas y a sus hermanas), lo que marca diferencias de poder entre los roles masculinos y femeninos (Sichra, 2004 en Lamas, 2007, p. 134). Los relatos a continuación ejemplifican estas realidades:

Yo le puedo decir también que vengo de un padre con violencia. Mi papá era muy malo, porque lo que mi mamá nos contaba era que ella no quería estar con mi papá, pero en esos tiempos que era donde los padres los obligaban a casarse con quien los padres elegían de marido. Entonces le tocó mi papá, pero mi papá era muy malo. Aparte de ser borracho, él siempre golpeó a mi mamá, por eso del día en que mi papá se murió, mi mamá nunca más quiso un esposo.

Investigadora: Y ese maltrato ¿igual sucedió delante de usted?

Entrevistada: Sí. Maltrato físico y psicológico. Y le puedo decir moralmente también, porque mi mamá le puedo decir que era su esclava de mi padre, porque nosotros vivíamos en el campo. Yo le puedo asegurar si no me cree, podría preguntar a cualquiera si usted va un día allá, de que mis hermanas mayores no estudiaron nunca, que la suerte la tuve yo y mi hermano. (Entrevistada 10)

Y mi papá no estaba en su sentido. Muchas veces me ha tirado con la botella o inclusive me ha insultado. Incluso, hubieron [sic] problemas más que todo como psicológico. Ambientalmente, psicológicamente yo me crie en un ambiente de violencia con mis papás. (Entrevistada 6)

Sicológica, verbal y todo. Física, toda la violencia de mi papá a mi mamá. Y yo no quiero terminar así. No puedo yo seguir los mismos pasos que mi padre y mi madre. (Entrevistada 8) 
Segundo, la migración apareció tempranamente en la vida de las mujeres como una forma de buscar salida a esta situación de violencia masculina familiar. Seis de las entrevistadas se fueron del hogar muy jóvenes, siendo aún adolescentes. Una entrevistada se fue "buscando la vida", ${ }^{9}$ según sus palabras, para dejar de vivir violencia dentro de su familia de origen:

Mis padres nunca vivieron felices, siempre peleaban ellos igual, o sea no había una tranquilidad en mi casa. Eh, por eso es que a los once años yo me fui de mi casa, porque ya no soportaba esa, esa cosa vivir en la casa porque todos los días verla a mi mamá llorar y con los ojos morete, o sea mi papá insultando, tratando de... No. Y es la misma cosa que yo pasé con mi pareja. Por eso es que nunca le avisé a mi mamá ni a mis hermanos. (Entrevistada 2)

Amigos nunca tuve, que mi mamá me hablara por lo menos tienes que cuidarte así, no. De aconsejar nada. No me aconsejaba de nada mi mamá. Y mi papá, en sí, qué me podía aconsejar, si siempre estaban violentándose entre ellos, insultándose, todo. (Entrevistada 8)

Tercero, muchas mujeres, al salir del ámbito de sus familias nucleares, y sin conocimientos sobre la prevención del embarazo (o sobre la sexualidad), terminan embarazándose en sus primeras experiencias con un hombre, aun adolescentes:

Eh, hui de mi casa con el papá de mis hijos a mis catorce años, pero fui haciendo vida de pareja a los quince, o sea ahí me embaracé de mi hija mayor, a los quince. (Entrevistada 7)

La maternidad les conduce, entonces, a formar una nueva familia. Pero, en la relación con el padre de sus hijos, se termina por reproducir la violencia que ellas observaron entre sus progenitores. Todas las mujeres entrevistadas han relatado haber sufrido alguna forma de violencia de parte de sus parejas (actuales o anteriores). Algunos de estos relatos dan cuenta de la gravedad y profundidad de estas experiencias de la violencia conyugal:

Entonces me estaba yendo, y lo tenía a Santiago [su hijo]. Santiago tenía como cinco meses. Me estaba yendo, el cual me agarra el brazo, me lo tira para atrás y yo quedo con Santiago en el suelo, entonces yo lo empujo, forcejeamos un rato el cual él me agarra de este lado y me dice "¡No te vas a ir! ¡No te vas a ir con mi hijo!”. Entonces me estaba ahorcando demasiado, entonces ya después de que ya me iba a desmayar lo tenía a Santiago del otro lado, entonces, me estaba por caer y cuando justo, justo llega la dueña de casa y gritó: "iSuéltela! ¡Suéltela! ¡La va a ahorcar, la va a asfixiar!”. Entonces agarró, hice que me suelte y yo, yo quedé ahí sentada, o sea no sabía ni lo que había pasado. Esa fue como que, me estaba ahorcando, me estaba ahogando demasiado rápido. Quedé ahí entonces yo, él ahí, a lo que yo me estaba parando me empuja y caí con Santiago. Entonces, en eso la señora, llamó a su mamá de él, su hermana, el cortejo de su hermana. Intentó volverme a pegar a mí, su mamá se metió, le pegó a su mamá. El cuñado se metió a defender a su suegra porque se estaba

\footnotetext{
${ }^{9}$ La expresión utilizada por la entrevistada (que para ella significa que se fue de su hogar en busca de una oportunidad de sobrevivencia) da título a un libro sobre las migraciones bolivianas del reconocido investigador Alfonso Hinojosa Gordonava (2009).
} 
teniendo a balancear a su hermana la menor. Entonces yo le dije "Melisa, llévenselo a Santiago". (Entrevistada 4)

Yo lo conocí en el colegio, éramos compañeros. Yo como al año de salir del colegio, me embaracé. Nació mi hija. Yo aún no vivía con él. Nació mi hija, como a los tres meses, me fui a vivir con él. Fue un infierno. Fue el infierno porque me encerraba en la casa, no me dejaba ver a mi mamá... Me golpeaba igual porque era como un enfermo de celos. Me encerraba, pero él llegaba a la casa mirando a la cama si había alguien. (Entrevistada 9)

Adicionalmente, se señala que al ocurrir los hechos de violencia con sus cónyuges o convivientes ocho de las 10 entrevistadas trabajaba fuera del hogar con remuneraciones. Es decir, constituían una fuente de renta familiar independiente a la de su pareja, por lo que podían considerarse autónomas económicamente. ${ }^{10}$ Inclusive así, vivieron fuertes episodios, reiterados y sistemáticos, tanto de violencia física, como psicológica, económica y sexual (Stolke, 2004).

Cuarto, sus relatos corroboran que la violencia de pareja es una causal de la migración. De las 10 entrevistadas, cinco manifestaron expresamente que aquella realidad, junto a la esperanza de una mejor inserción laboral (y, por ende, más autosuficiencia económica para que ellas puedan hacerse cargo de sus familias), fueron el impulso para migrar (Asakura \& Torres Falcón, 2013):

Mira, yo Bolivia, decidí dejar porque económicamente allá, aquellos años no estaba bien, ni ahora estamos bien, porque hay trabajo, hay empleo, no es que no... Pero lo que uno gana no alcanza y aparte de eso salí porque sufría mucho, igual la violencia con, con el papá de mis hijos. Él era un borracho, era un mujeriego, era un celoso, él me golpeaba... la ley es muy mala en mi país. Eh... Me da vergüenza decirlo, pero lo digo así, porque no es bueno como aquí en Chile. (Entrevistada 2)

Investigadora: ¿Por qué motivo decidió venir a Chile?

Entrevistada: Uno económico y escapar más que todo de los brazos del papá de mi hijo.

Investigadora: ¿A qué se refiere con escapar de los brazos del papá de su hijo? Entrevistada: O sea, no llevamos una relación muy buena. Se basaba en los gritos, pelea, engaños... Entonces más que todo por, era muy constante mmm. Tenemos muchas amistades este en común, entonces a los lugares donde yo iba tenía que estar él y las veces que estaba ahí él siempre era para humillar o sacar en cara algo, o ver yo que él estaba con otra persona, entonces más que todo por eso decidí venir acá. Poder darle una vida mejor a mi hijo y tanto como yo también tratar de olvidarme de todo. (Entrevistada 4)

Sí. Yo viví esa vida de no tener papá, entonce' yo no quería eso para mi hijo. Porque yo sufrí mucho y porque yo tenía un padrastro. Había días que comía y días que no comía, tonce' no. No quería que mi hijo pasara por eso y tuve

\footnotetext{
${ }^{10}$ La autonomía económica se explica como la capacidad de las mujeres de generar ingresos y recursos propios a partir del acceso al trabajo remunerado en igualdad de condiciones que los hombres. Considera el uso del tiempo y la contribución de las mujeres a la economía (Observatorio de Igualdad de Género de América Latina y el Caribe, s. f.).
} 
que aguantarme nomás, todo. No podía hacer nada. Tonce' pensaba en mi cabeza, me voy a ir primero, me voy a ir a Chile porque ya no aguantaba ya. Él empezó a andar má' tenía su auto, iba a ver niñas y su familia no le decía nada, sus hermanas le decían: "Ay, que esta ignorante". Una guagua. Como una guagua lo vestía. "Ay déjala". Así le decían sus hermanas, son machistas igual, igual se hacen pegar y yo aguantaba. (Entrevistada 5)

En este punto es importante mencionar que en general se enuncia la globalización como un telón de fondo que promueve un choque entre las concepciones de género de la sociedad de procedencia y la de recepción, en el entendido de que cada sociedad puede indicar ciertas modalidades y/o expresiones de lo que es considerado como feminidad y masculinidad (Cea-Merino et al., 2015, p. 34). En este sentido, de acuerdo con los relatos de las 10 entrevistadas, ocho declararon haber vivido violencia económica en Bolivia y/o en Chile.

Quinto, estas experiencias de violencia con sus parejas han tendido a reproducirse entre aquellas mujeres para quienes la migración fue una decisión familiar, emprendida a la par con sus compañeros. En estos casos, las violencias sufridas cruzan las fronteras hacia Chile (Asakura \& Torres Falcón, 2013), como vemos en el duro relato que sigue:

Sí era eso, entonces sabía que él iba... Sabía que él tenía dominio del dinero y me daba miedo, así que callaba y los golpes vinieron de una vez que en Calama [ciudad de la región de Antofagasta, Chile]... Bueno esta historia le voy a contar. De por todos los golpes que vinieron, él siempre estaba fijándose que yo en la casa estaba. Entonces cuando mis hijos el primer día de clases ellos fueron a primero básico y llegué a casa en la tarde, después de dejarles en el colegio y dije "wow, tengo libre y veré una película". Porque siempre mis hijos veían con el papá y no veían lo que yo quería ver y dije: "ahora voy a aprovechar y primer día libre". Entonces fui y alquilé una película. Llegué a la casa y me puse una bata, porque no había nadie, me serví una limonada y estaba sola. Me sentía como: "bueno voy a descansar un rato y voy a ver una película". Y me eche, estaba mirando la película y de pronto siento alguien llegar y abre la puerta él. Y fue él, yo me asusté porque él no me encontró trabajando ¿Entiende? Porque yo siempre si no estaba descansando o haciendo algo era una vaga. Por eso me daba miedo que me encuentre así. Entonces, cuando me encontró ahí con la bata y todo y empezó a revisar los roperos y dio vuelta la cama... Sí, y yo miré y dije: “¿qué te pasa?”. “¿Quién está acá?”. Y me dolió que pensara eso y revisó todo y después ahí fue que me dijo: “¿con quién estabas?”. Y encontró que justo me compré un sostén nuevo y revisó la parte de la ropa interior, que había nuevas cosas que me compré. Porque, bueno, ya estaban viejos y justo me compré. Y él se fue, regresó y ahí me golpeó. Me tiró al piso y me dijo: “¿con quién estabas?”. La verdad es que él me apretaba tanto del cuello, porque él siempre se subía arriba de mí, se sube encima de mí y yo sé que no puedo hacer nada. Me aprieta el cuello y me dice: "¿con quién has estado? ¿has estado con alguien? Dime ¿con quién has estado?" Y yo le digo que me suelte porque no podía respirar y le dije "sí estuve con alguien" (llanto). Quise vivir. Y me soltó y: "quizás vas a tener sida o algo y me estás contagiando". Ya no podía decirle que no y me callé. Y ahí empezaron los golpes. (Entrevistada 1) 
Esta entrevistada manifestó haber vivido violencia física, sexual, económica, psicológica e institucional (por el pastor de la iglesia), tanto en Bolivia (a través de su familia de origen) como en Chile con quien fue su cónyuge.

Estas cinco características sobre la violencia relatadas por las mujeres nos permiten observar que dichas experiencias son elementos centrales en su trayectoria vital y son esenciales, además, en todos los momentos de sus desplazamientos migratorios (Tapia Ladino, 2011; Asakura \& Torres Falcón, 2013).

\section{El conocimiento sobre la protección estatal}

En el presente apartado se muestra qué tipo de conocimiento tienen las mujeres sobre los marcos jurídicos e instituciones estatales de protección que están a su alcance tanto en Chile como en Bolivia.

Antes de entrar en este tema, conviene abordar la visión de la propia institucionalidad chilena que atiende a estas mujeres migrantes en Tarapacá. Como se ha explicitado en la introducción, entre los años 2018 y 2019, en la región se registró un aumento del número de bolivianas recibidas en los centros de la mujer y casas de acogida. Para entender la perspectiva institucional sobre este fenómeno, se realizó una entrevista con un agente de dicho Servicio. Desde su parecer, el aumento de la cobertura de estas mujeres se debe a un cambio en la acción del Estado, es decir,

A un acercamiento del Servicio a las mujeres, desde los distintos operativos que hemos hecho, el gobierno en terreno o del mismo trabajo que hace de difusión el Centro de la Mujer, en Extranjería también. Un trabajo donde se le informa a las mujeres que nosotros no hacemos exclusión a la hora de las atenciones. Atendemos a inmigrantes independiente de su calidad, ver si están con sus papeles al día o no. Entonces, eso también ha permitido que las mujeres puedan llegar más a nuestro dispositivo y que nos tengan la confianza a nosotros para poder atenderlas oportunamente. Yo creo que también ha impactado en la creciente llegada de migrantes también a Tarapacá, siempre hemos tenido migración en Tarapacá, históricamente [Iquique] es una ciudad que ha recibido muchos migrantes. Pero el último tiempo hemos tenido una creciente llegada de migrantes y eso también incide, yo creo, en que tengamos más mujeres de distintas nacionalidades en las casas de acogida y en los centros de la mujer. (Agente informante Dirección Regional)

De igual forma, al ser consultado sobre cómo están enfrentado este aumento de participantes y residentes, respondió que a nivel regional:

Tenemos que hacer un trabajo importante el año 2020, para acercarnos más al territorio, ir más a las juntas de vecinos e informar más de lo que hacemos para que podamos tener llegada con todas aquellas mujeres que están siendo víctima de violencia y que no saben. (Agente informante Dirección Regional)

Pero, más allá de este entusiasmo del agente, el servicio de protección contra la violencia de género sigue sin ser conocido por parte relevante de las mujeres migrantes en Tarapacá. Esto es lo que arrojan las entrevistas. Al ser consultadas sobre el conocimiento de la institucionalidad chilena en la materia, partiendo por saber 
si están al tanto de a qué organismo acudir en caso de vivir hechos de violencia de pareja, las respuestas de las 10 entrevistadas fueron contundentes. Solo tres de ellas aseveraron conocer dónde pueden concurrir. Siete desconocen la información.

Por otro lado, la institución del Estado más nombrada por las entrevistadas cuando indagamos a quienes recurren en casos de violencia fue Carabineros de Chile, pues, saben que pueden efectuar las respectivas denuncias. La segunda institución más mencionada es el Poder Judicial. Las mujeres nos cuentan que la reacción de los jueces a los agresores resulta una importante barrera a la reproducción de la violencia. Así, el poder judicial chileno aparece como un espacio donde las mujeres sienten que sus denuncias son escuchadas y reconocidas:

Sí, porque cuando me dijeron tú puedes ir a la policía y lo llevaron a él no pude creerlo y cuando un juez le dijo que estaba mal eso me gustó mucho que alguien diga que está mal lo que estaba haciendo, o sea, que al fin alguien me dejó de golpear, te sientes bien es como que alguien le previene que no lo haga más aunque lo volvió a hacer, pero ya supe que tuve esa opción para poder llamar a alguien a la policía, para que pudieran ayudarme. (Entrevistada 1)

Sí... acá sí puedo denunciar. Acá sí hay ley. Si por ejemplo si yo hubiera sufrido maltrato, golpe. Así como he sufrido en Bolivia con este mi pareja yo le iba a denunciar, él hubiera estado dentro quizás. (Entrevistada 2)

Le voy a decir la única vez que me sentí bien fue en el juzgado cuando Andrés [su expareja] dijo “iyo soy la víctima aquí!, ¿ ¿por qué me están juzgando?”. Y el juez se levantó y le dijo: “¡usted sabe por qué está acá! ¡Usted golpeó a su esposa!”. Es que es primera vez que alguien le dijo que estaba mal y de ahí mi mente cambió y dije: “¿Carmen, qué estás haciendo?”. O sea, te golpeó alguien y tú siempre dices que estás bien, yo decía, incluso: "te mereces que te peguen". Hasta yo lo creía, fui tan tonta pensando "pucha, te mereces también, debes dejar, porque todos los hombres miran mujeres, todos los hombres les gustan las mujeres". Pero humillando no tanto, o sea, yo creo que hasta tienen que humillarme estaría bien, no sé. (Entrevistada 1)

En el caso de la Entrevistada 1, es la actuación del juez chileno frente a su excónyuge lo que le permitió reconocer su calidad de víctima de violencia dentro del proceso judicial. Lo anterior se desencadena a raíz de los dichos del juez que conoció la causa, lo que se vincula directamente con el restablecimiento de la dignidad de una persona a través del derecho. Pero esta no es la realidad de la mayor parte de nuestras entrevistadas que han relatado desconocer los mecanismos y servicios de protección que existen en Tarapacá y en Chile:

Investigadora: Y acá en Chile ¿usted sabe lo que debe hacer si le llega a pasar algo similar?

Entrevistada: Aquí no. Porque digamos, no sé a qué punto ir, llegar, o a donde ir. Investigadora: Y, ¿ha escuchado alguna vez hablar de la Policía de Investigaciones, de Carabineros?

Entrevistada: Sí, he escuchado. Pero si bien, no, no conozco, digamos.

Investigadora: $\mathrm{Y}$ ¿ha escuchado hablar del Sernameg?

Entrevistada: No.

Investigadora: ¿Del centro de la mujer? 
Entrevistada: Eso no he escuchado.

Investigadora: ¿Casas de acogida?

Entrevistada: Solo he escuchado ley. (Entrevistada 3)

Le explicamos al agente que, entre las entrevistas realizadas a 10 mujeres bolivianas residentes por más de dos años en la región, todas habían sido víctimas de violencia de pareja, pero tan solo una de ellas había tenido alguna información sobre el servicio de las casas de acogida. Sobre esto, el agente comentó:

Un tema pendiente que nos queda es trabajar en la sensibilización de la prevención de la violencia y en llegar a más mujeres a través de estos territorios cercanos, unidades vecinales. Eso, eso es como lo que tenemos pensado. (Agente informante Dirección Regional)

Pero nuestras entrevistas revelan datos interesantes respecto al conocimiento, experiencias y/o percepciones de la institucionalidad boliviana competente en lo que concierne a la protección de la violencia de género. Si en Chile ellas desconocen los mecanismos e institucionalidades, en Bolivia lo conocen plenamente. Ocho de las 10 entrevistadas sabían dónde podían denunciar:

Entrevistada: En Bolivia, sí. Igual iría a denunciar. Pero sé que en Bolivia no van a hacer nada. Conociendo cómo es la ley allá, yo no tengo mucha fe con la ley.

Investigadora: Y allá ¿dónde denunciaría?

Entrevistada: Eh... voy igual así, a la brigada como nosotros le llamamos, donde hay para la defensa para las mujeres. Pero no hace nada. No. Uno pierde su tiempo cuando va a denunciar allá. (Entrevistada 2)

Entrevistada: Yo fui, lo denuncié en la Brigada de la Mujer, porque nosotros igual tenemos allá y lo que me decían allá era "ah es su marido, son cosas de borrachos. Vaya a su casa nomás. Vuelva”. Entonces, no fue el apoyo que yo quería. Este me decía "Si gusta, usted pasa la noche acá. Acá nos va hacer compañía a todos". Eran puros hombres.

Investigadora: ¿Fuiste atendida ¿solo por hombres?

Entrevistada: Sí, solo por hombres. Los cuales me dijeron su marido es cosa de borrachos.

Investigadora: $\mathrm{Y}$, ¿le tomaron la denuncia?

Entrevistada: No me tomaron nada. Me dijo "vuelva a su casa. Vuelva a su casa y hable con él, porque es su marido".

Investigadora: $\mathrm{Y}$ de acuerdo con la experiencia que tuvo allá con la Brigada de la Mujer, con la Defensoría de la Niñez en el caso de tu hijo, ¿cómo siente que fue ese proceso?

Entrevistada: De que no me han ayudado para nada. Sentía como, me sentía sola, sola. Como si yo contara a alguien y ese alguien no me fuera ayudar como yo esperaba que me ayudaran. Entonces me sentía sola, con tal de que esperaba yo iba, me decía "véngase el miércoles", iba el miércoles "ah nada, todavía nada". Entonces "véngase el viernes a ver qué le dice, que le dice el juez". Y así, así pasaba y casi nunca se movían. Y así es cuando difícilmente una mujer busca ayuda. Y tenemos así las carpetas, que nada. Que nada miraban, lo pasaba, lo miraba, lo pasaba. (Entrevistada 4) 
Investigadora: ¿Usted sabe que los actos que él realizó constituyen delito en Bolivia? Por ejemplo, los malos tratos, insultos, golpearla.

Entrevistada: Sí, pero cuando uno denuncia no hacen nada.

Investigadora: Pero usted, ¿efectuó alguna denuncia?

Entrevistada: No, yo no porque he visto. Yo veía porque también tenía ese temor. Será porque la mujer permitía eso, no sé, pero yo lo veía. Por ejemplo, con mi mamá, también se hacía pegar, le demandaba, le pegaba mi mamá, bien pega'o mi padrastro que tenía, le pegaba y lo llevaban preso, mañana ya estaba afuera. Volvía, con más ganas le pegaba porque eran denuncias y me daba miedo a mi igual eso. Pero ahora veo que han cambiado igual las cosas y, ahora yo que estoy acá en Chile, veo las cosas muy diferentes. No es lo mismo que vivía allá yo [...] Antes era Defensa, antes llamaba uno iban al defensa no más antes. Y a la Brigada de la Mujer te dicen, así como, por ejemplo, cuando uno va a denunciar te dicen "Ya po, ¿qué van a hacer? Tiene que pensar. ¿Van a volver?". No te dan esa ayuda sicológica como acá, por ejemplo, cuando a uno le pegan, te dicen "¿qué vas a hacer?". Yo veo acá, es diferente. A mí, me ayudaron harto para que usted sepa. Mire allá, no hay eso. Te dicen "Ya po, entonce' le doy una semana, vayan a ver cómo se arreglan o no, vuelven después y le hacemos los papeles si se separan o no para pasar así nomás". Y allá la mayoría en estas cosas, el hombre es el que tiene plata, el hombre va a salir más favorable allá.

Investigadora: Pero ¿a quién pagan?

Entrevistada: Al mismo, como se llama, esa misma institución po. Hay policías, tonce' ahí mismo le paga una plata y no pasa nada po. Limpian una hoja. Tonce' a mí, como, cómo le puedo decir, esa confidencialidad ya tenía miedo, pa' que iba a ir si, le iba, se va a llevar preso, va a volver igual, lo va a hacer con más ganas va a pegar. Y eso me pasa a mí.

Investigadora: ¿Eso la desmotivó a poder denunciarlo?

Entrevistada: Sí. (Entrevistada 5)

Entonces, irrumpió otro dato relevante: pese a conocer los servicios y sus canales, su experiencia y/o percepciones sobre el proceso y funcionamiento de los organismos bolivianos es que no funcionan bien o reproducen el problema de la violencia, lo que las desincentiva a denunciar y que sus casos se ventilen ante un tribunal de justicia. Resultados que se condicen con las apreciaciones del xvi Informe a la Asamblea Legislativa Plurinacional de Bolivia, elaborado por la Defensoría del Pueblo, (2014).

\section{Consideraciones finales}

Este estudio de caso permite situar diversas consideraciones finales. Entre ellas, principalmente seis.

Primero, a través de los resultados que aportaron las entrevistas se pudo constatar que efectivamente la violencia que sufrieron las entrevistadas, en particular la doméstica, motiva la migración de mujeres a la región chilena de Tarapacá. También se puede considerar que la exposición de las mujeres a actos de violencia más graves 
se agudiza cuando ellas se encuentran en situación migratoria irregular, conforme a la información proporcionada por el Sernameg. Lo anterior expone a las mujeres en condición irregular a mayores vulnerabilidades.

Segundo, todas las entrevistadas, fueron víctimas directas o indirectas, durante su infancia, al interior de su familia de origen, de violencia física y psicológica. Luego, esa realidad se repitió precisamente con el padre de sus hijos, inclusive, lo que en ocasiones llegó a ser normalizado por las entrevistadas. A pesar de que muchas de las entrevistadas llegaron a contar con redes de apoyo y una autonomía económica (comenzaron a trabajar a edad temprana, y asumieron, como inherente a su rol de mujer, el ser encargadas de las obligaciones productivas y reproductivas), este empoderamiento económico no se tradujo en una salvaguardia frente a la violencia masculina.

Tercero, se puede concluir que la legislación chilena en materia de violencia contra la mujer debe ser ampliada respecto a los tipos de violencia que deben ser reconocidos legalmente y sancionados. Esto a fin de extender la esfera de protección para ajustarla a los estándares internacionales exigidos a través de los diferentes tratados que se han suscrito. La aplicación de la ley, además de su fin regulatorio, consagra e incluso produce en las afectadas la posibilidad de autocomprenderse como tales y buscar las formas de dar término a la desigualdad en la que viven.

Cuarto, es relevante poner énfasis en la sensibilización sobre esta realidad en la comunidad nacional y migrante regional. Sobre todo, dar a conocer las instituciones chilenas competentes, con énfasis en la orientación y reparación de las mujeres que han sido víctima de violencia de pareja. Especialmente, en virtud del aumento reciente de participantes y residentes bolivianas de los dispositivos del Sernameg en Tarapacá, una propuesta del mismo agente informante entrevistado fue trabajar directamente con dirigentes migrantes locales, a fin de extender la entrega de información institucional a la mayor cantidad de mujeres, haciendo hincapié en que no importa el estatus migratorio al momento de ser víctimas de violencia y que en los casos de violencia grave existe una visa que permite regularizar su situación migratoria.

Quinto, en cuanto a la legislación boliviana, es destacable que en esta materia cuente con un desarrollo mucho más actualizado y acorde a lo planteado en este artículo. No obstante, desde los relatos obtenidos y del estudio de la Defensoría del Pueblo (2014), existe una gran diferencia entre lo consagrado en la ley y el funcionamiento de las instituciones políticas competentes, las cuales terminan incentivando y reproduciendo la violencia de tipo institucional.

Por último, al considerar que frente a episodios de violencia grave vividos por las mujeres entrevistadas, estas decidieron huir de su país de origen hacia Chile, que la mayoría ejerce labores remuneradas fuera de su hogar y que con los requisitos de la nueva ley de extranjería, en general, se dificulta el acceso para obtener la residencia, puede darse un tipo más grave de violencia de género, que es la trata de personas, por ende, es necesario estar monitoreando esta realidad.

\section{Agradecimientos}

La autora agradece a la Agencia Nacional de Investigación y Desarrollo de Chile que financia el estudio que originó el presente artículo a través del proyecto Fondecyt 1190056: "The Boundaries of Gender Violence: Migrant Woman's Experiences in South American Border Territories". 


\section{Referencias}

Acosta González, E. (2013). Mujeres migrantes cuidadoras en flujos migratorios sursur y sur-norte: expectativas, experiencias y valoraciones. Polis, Revista Latinoamericana, 12(35), 2016, 35-62. https://scielo.conicyt.cl/pdf/polis/v12n35/ art03.pdf

Anthias, F. (2012). Transnational mobility, migration research and intersectionality. Nordic Journal of Migration Research, 2(2), 102-110. http:/ /dx.doi.org/10.2478/ v10202-011-0032-y

Asakura, H. \& Torres Falcón, M. (2013). Migración femenina centroamericana y violencia de género: pesadilla sin límites. Zona Franca. Revista del Centro de Estudios Interdisciplinarios sobre Mujeres, 21(22), 75-86. https:// rephip.unr.edu.ar/bitstream/ handle/2133/12200/Migraci\%C3\%B3n\%20femenina\%20centroamericana\%20 y $\%$ 20violencia $\% 20 \mathrm{de} \% 20 \mathrm{~g} \% \mathrm{C} 3 \%$ A9nero.pdf?sequence $=3$

Asamblea General de las Naciones Unidas. (1993). Declaración sobre la eliminación de la violencia contra la mujer. Oficina del Alto Comisionado de las Naciones Unidas para los Derechos Humanos. https://www.ohchr.org/sp/professionalinterest/ pages/violenceagainstwomen.aspx

Asamblea Legislativa Plurinacional. (2013). Ley 348. Ley integral para garantizar a las mujeres una vida libre de violencia (Bolivia). https://oig.cepal.org/sites/default/ files/2013_bol_ley348.pdf

Barragán, R. (1996). Miradas indiscretas a la patria potestad: articulación social y conflictos de género en la ciudad de La Paz, siglos XviI-XIX. En D. Y. Arnold (Comp.), Más allá del silencio. Las fronteras de género en los Andes. Editorial CiAsE/ ILCA.

Cea-Merino, P., Galaz Valderrama, C. \& Montenegro-Martínez, M. (2015). La construcción social de las mujeres inmigrantes en los discursos de la academia. Psicoperspectivas, individuo y sociedad, 14(2), 28-39. https://scielo. conicyt.cl/pdf/psicop/v14n2/art04.pdf

Centro de Derechos Humanos. (2017). Violencia contra la mujer en Chile y derechos humanos (informe temático 2017). Facultad de Derecho-Universidad de Chile. https://www.uchile.cl/documentos/descarga-el-informe-violencia-contra-lamujer-en-chile-y-derechos-humanos-pdf-29-mb_141701_0_4543.pdf

Chiarotti, S. (2006, junio). Aportes al derecho desde la Teoría de Género. Otras Miradas, 6(1), 6-23. http:/ /www.redalyc.org/articulo.oa?id=18360102

Cifuentes V., P. \& Weidenslaufer, C. (2019). Violencia contra la mujer. Derecho comparado. Asesoría Técnica Parlamentaria/Biblioteca del Congreso Nacional de Chile. https://www.bcn.cl/obtienearchivo?id=repositorio/10221/27302/2/BCN_Violencia_contra_la_mujer_Derecho_comparado_2019.pdf

Coordinadora de la Mujer. (2019). Situación de las mujeres en Bolivia. http://www.coordinadoradelamujer.org.bo/observatorio/archivos/destacados/boletin8mcompressed_86.pdf

De Beauvoir, S. (1997). El segundo sexo. Siglo xx.

Defensoría del Pueblo. (2014). XVI Informe a la Asamblea Legislativa Plurinacional. https:/ / www.defensoria.gob.bo/uploads/files/xvi-informe-a-la-asamblea-legislativa-plurinacional-2013.pdf 
Espín, O. (2010). Is domestic violence a cultural tradition?.. and other questions about gender and migration [Conferencia]. US Embassy en Viena, Austria. https://olivaespin. sdsu.edu/downloads/Is_domestic_violence_a_cultural_tradition.pdf

Guaygua, G. \& Castillo, B. (2008). Atrapadas en las redes sociales. Prevención, de la violencia familiar en El Alto, Quime, Cochabamba, Santa Cruz. Centro de Promoción de la Mujer Gregoria Apaza.

Guaygua, G., Castillo, B., Prieto, P. \& Ergueta, P. (2010). La familia transnacional. Cambios en las relaciones sociales y familiares de migrantes de El Alto y La Paz a España. Defensor del Pueblo/Pastoral de Movilidad Humana/Fundación PIEB.

Herrera, G. (2013). Gender and international migration: contributions and cross-fertilizations. The Annual Review of Sociology, 39, 471-489. https://www.annualreviews.org/doi/pdf/10.1146/annurev-soc-071811-145446

Hinojosa, A., Pérez, L. \& Cortez, G. (2000). Idas y venidas. Campesinos tarijeños en el norte argentino. Fundación PIEB.

Hinojosa Gordonava, A. R. (2009). Buscando la vida. Familias bolivianas transnacionales en España. Clacso/Fundación PIEB. http://biblioteca.clacso.edu.ar/clacso/becas/20120418053427/lavida.pdf

Instituto Nacional de Estadísticas del Estado Plurinacional de Bolivia. (2018). 52 de cada 100 mujeres solteras tuvieron algún tipo de violencia. https://www.ine.gob.bo/ index.php/52-de-cada-100-mujeres-solteras-tuvieron-algun-tipo-de-violencia/

Instituto Nacional de Estadística \& Departamento de Extranjería y Migración. (2021). Estimación de personas extranjeras residentes habituales en Chile al 31 de diciembre de 2020. Distribución regional y comunal. https://www.extranjeria.gob.cl/media/2021/08/Estimación-población-extranjera-en-Chile-2020-regiones-y-comunas-s\%C3\%ADntesis.pdf

Lagarde, M. (2006). Del femicidio al feminicidio. Desde el jardín de Freud, (6), 216-225. http://repositorio.ciem.ucr.ac.cr/bitstream/123456789/9/3/RCIEM002.pdf

Lamas, M. (2007). Género, desarrollo y feminismo en América Latina. Pensamiento iberoamericano, (0), 133-152. https://dialnet.unirioja.es/servlet/articulo?codigo $=2872536$

Leiva Gómez, S. (2015, enero-junio). Organización social del cuidado en Bolivia y Chile: Estado y ciudadanía. Revista Austral de Ciencias Sociales, (28), 61-81. http:// www.redalyc.org/articulo.oa?id=45955899004

Lube Guizardi, M., Gonzálvez Torraldo, H, \& Stefoni C. (2018). De feminismos y movilidades. Debates críticos sobre migraciones y género en América Latina (19802018). Revista Rumbos TS. Un Espacio Crítico para la Reflexión en Ciencias Sociales, 13(18), 37-66. http://revistafacso.ucentral.cl/index.php/rumbos/article/ view $/ 6$

Ministerio del Interior de Chile \& Servicio Nacional de la Mujer. (2009, 16 de diciembre). Convenio de colaboración conjunta entre el Ministerio del Interior y el Servicio Nacional de la Mujer. Resolución Exenta $N^{\circ} 80388$. https:/ /oig.cepal.org/sites/default/ files/2009_res80388_chi.pdf

Ministerio del Interior y Seguridad Pública. (2021). Ley 21325. Ley de Migración y Extranjería (Chile). https://www.bcn.cl/leychile/navegar?idNorma=1158549 
Nash, J. (2008). Rethinking intersectionality. Feminist Review, (89), 1-15.

Observatorio de Igualdad de Género de América Latina y el Caribe. (s. f.). Autonomía económica. Comisión Económica Para América Latina y el Caribe (Cepal). https://oig.cepal.org/es/autonomias/autonomia-economica

Ovando, C. \& Ramos R. (2016, 1 de febrero). Imaginarios geográficos en torno a la franja fronteriza de Tarapacá: el Estado y los habitantes/migrantes. Scripta Nova. Revista electrónica de Geografía y Ciencias Sociales, 20(529). http://www.ub.edu/ geocrit/sn/sn-529.pdf

Parella, S. \& Reyes, L. (2019). Identidades interseccionales: mujeres migrantes poblanas con estatus migratorio indocumentado en Nueva York. En H. Gonzálvez Torralbo, D. C. Fernández-Matos \& M. N. González Martínez (Comps.), Migración con ojos de mujer. Una mirada interseccional (pp. 85-118). Ediciones Universidad Simón Bolivar. https://bonga.unisimon.edu.co/bitstream/ handle/20.500.12442/4365/Migraci\%c3\%b3n_OjosdeMujer_PDF.pdf?sequence $=1$ \&isAllowed $=\mathrm{y}$

Peredo Beltrán, E. (2004). Una aproximación a la problemática de género y etnicidad en América Latina (Serie Mujer y Desarrollo 53). Comisión Económica para América Latina y el Caribe. https://repositorio.cepal.org/bitstream/handle/11362/5919/1/S04141_es.pdf

Rico, N. (1996). Violencia de género: un problema de derechos humanos (Serie Mujer y Desarrollo 16). Comisión Económica para América Latina y el Caribe. https:// repositorio.cepal.org/bitstream/handle/11362/5855/S9600674_es.pdf

Segato, R. L. (2003). La argamasa jerárquica: violencia moral, reproducción del mundo y eficacia simbólica del derecho (Serie Antropología). Universidade de Brasilia http:/ / dan.unb.br/images/doc/Serie332empdf.pdf

Subsecretaría de Prevención del Delito. (2016). Delitos de violencia intrafamiliar-casos policiales 2005-2016. http://www.seguridadpublica.gov.cl/estadisticas/tasa-de-denuncias-y-detenciones/delitos-de-violencia-intrafamiliar-casos-policiales/

Stolke, V. (2004, mayo-agosto). La mujer es puro cuento: la cultura del género. Revista Estudios Feministas, Florianapolis, 12(2), 77-105. https://doi.org/10.1590/S0104026X2004000200005

Tapia Ladino, M. (2011). La migración como escenario para la comprensión de la violencia de género entre migrantes internacionales. Amérique Latine Histoire et Mémoire. Les Cahiers ALHIM, (21). https://doi.org/10.4000/alhim.3733

Tapia Ladino, M. \& Ramos Rodríguez, R. (2013). Mujeres migrantes fronterizas en Tarapacá a principios del siglo xxi. El cruce de las fronteras y las redes de apoyo. Polis, 12(35), 229-257. http://dx.doi.org/10.4067/S0718-65682013000200011

Tubert, S. (Ed.). (2003). Del sexo al género. Los equívocos de un concepto. Ediciones Cátedra.

Vives-Cases, C., Gil-González, D., Plazaola-Castaño, J., Montero-Piñar, M. I., Ruiz-Pérez, I., Escribà-Agüir, V., Ortiz-Barreda, G. \& Torrubiano-Domínguez, J. (2009). Violencia de género en mujeres inmigrantes y españolas: magnitud, respuestas ante el problema, políticas existentes. Gaceta Sanitaria, 23(Supl 1), 100-106. https:// doi.org/10.1016/j.gaceta.2009.07.008 
Mileska Romero

Chilena. Magíster en relaciones internacionales y estudios transfronterizos, Universidad Arturo Prat-Chile. Actualmente es estudiante de magíster en derecho en la Pontificia Universidad Católica de Valparaíso, Chile. Líneas de investigación: estudios sobre derecho migratorio. Publicación reciente: Liberona Concha, N., Salinas S-g., Veloso, K. \& Romero, M. (2021). Tipología de cuerpos traficados desde América del Sur hacia Chile. Antípoda. Revista de Antropología y arqueología, (44). https://doi.org/10.7440/ antipoda44.2021.08 